\title{
Exploring the need for a responsive school curriculum to cope with the Covid-19 pandemic in Pakistan
}

\author{
Rani Gul $^{1}$ (D) $\cdot$ Gulab Khilji $^{2}$ (D)
}

Accepted: 27 December 2020 / Published online: 4 March 2021

(C) UNESCO IBE 2021

\begin{abstract}
The article investigates the response of the Pakistani curriculum to the Covid19 outbreak. It also looks into the development of a curriculum that addresses the specificities of students' situations, while reminding them of global connectedness. The article is based on semi-structured interviews with 10 curriculum experts, 20 principals, and 35 teachers, as well as content analysis of the 2018 National Curriculum Framework of Pakistan. Its findings reveal participants' disappointment with the top-down, predetermined nature of the curriculum, which makes it inadequate for situations such as the Covid-19 pandemic. The curriculum was perceived as being highly rigid, with little room for alternative modalities. Participants believed the curriculum could not support children's learning in normal times, much less during a pandemic. Therefore, this article suggests a complete revamping of the curriculum and strengthening of teachers' capabilities. It also suggests curricular material be updated to make it context specific, responsive to the needs of learners, and supportive of independent learning.
\end{abstract}

Keywords Covid-19 crisis · Curriculum · Curriculum responsiveness · Learning · Pakistan

At present, the world seeks insight into, knowledge of, and solutions to the myriad challenges confronting the education sector due to the Covid-19 pandemic (Gul and Khilji 2020). A country's needs, as well as the needs dictated by a rapidly changing working world, directly affect the educational environment and the ability to ensure a career-oriented

Rani Gul

dr.rani27@gmail.com

Gulab Khilji

gulab_khilji@hotmail.com

1 Department of Education, University of Malakand, Chakdara, Dir Lower, Khyber Pakhtunkhwa, Pakistan

2 Bureau of Curriculum Secondary Education Department, Quetta, Balochistan, Pakistan 
experience and maximize individual development (Hayes and Juárez 2012). Since the world changes so rapidly, school curricula become outdated fast, creating a gap between learning and social and practical work situations (Ullah 2020). It is therefore crucial for education systems to reform their curriculum, to respond to changes in society; and to form a learning society that liberates every person's creative and intellectual energies and prepares them for a world in which knowledge and multifaceted interactions are the keys for achieving success and economic expansion.

As in other developing countries, the Covid-19 pandemic has negatively affected the education of millions of students in Pakistan (Gul and Khilji 2020), a country that is already accustomed to 10 million children being out of school throughout the year (Rahman 2020). Since the end of the pandemic does not seem imminent, private schools have started an online system of education to save students' careers. However, due to limited resources and technology, public schools have been hesitant to embark on such initiatives. To facilitate the education of public-school students, the Ministry of Federal Education and Professional Training has started a tele-school system of education that uses a national television channel to disseminate student learning outcome (SLO)-based educational content for grades 1 through 12. Nevertheless, parents, teachers, and educational stakeholders have growing concerns regarding the efficacy of this system with respect to students' short-term learning and long-term success. Even if it overcomes the unpredictable and far-reaching challenges of such a delivery system, curriculum can appear to be set in stone, stuck in the past, unable to respond in timely ways, struggling to catch up or adapt, or critical of the status quo; it can even appear to get ahead of the curve. This is a serious blind spot, one that could undermine the Education 2030 Agenda (Pinar 2020).

The Covid-19 pandemic is a stark reminder of the critical necessity for curriculum to become more responsive and proactive, perhaps even refocusing curricular time away from traditional school subjects and toward timely topics, the understanding of which would be informed by traditional school subjects (Pinar 2020). To fulfill the widespread demand for curriculum reforms, higher educational institutes in Pakistan have implemented innovations to ensure improvement in interdisciplinary curricula by allowing greater flexibility in course content and modes of delivery, as well as in the assessments linked to social and work-related problems, and by allowing students to take greater responsibility. All these innovations aim at increasing a curricular response to emerging social needs. However, at the school level, the existing curriculum, established in 2006, still requires the education stakeholders' attention to implement innovations. Therefore, in this article, we aim to determine whether the existing school curriculum responds to and supports fast-changing, unpredictable, and often disruptive events, such as the outbreak of Covid-19. Additionally, we seek to suggest proposals for the development of a responsive curriculum that addresses the specificities of students' situations, while reminding them of global connectedness.

\section{The process of curriculum development in Pakistan}

In the curriculum development process, what is taught, who is taught, and how it is taught are systematically organized. Every component affects and interacts with the others. For example, who is being taught (their age, maturity, education level) is affected by what is being taught. Methods of teaching content vary according to who is being taught, the characteristics, and the environment. The following are considered important factors of non-formal learning in light of these three basic components. Curriculum experts have 
suggested sequenced interventions, or steps, for curriculum preparation and development. For instance, Taba (1962) described six major steps in curriculum development (Figure 1).

In sum, the curriculum reform process comprises the following: (a) diagnosing students' learning needs, (b) stating learning goals and objectives, (c) selecting appropriate content, (d) organizing content and learning experiences, (e) developing delivery strategies and conducting evaluations, and (f) conducting research and assessment of the field.

These six steps include various complex courses of action, research, reflection, contemplation, and choices between different alternatives. Each contains two distinct steps. At each stage of decision making, however, utmost care must be taken. Considering the curricular requirements and set procedures, we developed the following overarching questions for the current study:

- To what extent did the school curriculum respond to address the Covid-19 pandemic in Pakistan?

- In light of the Covid-19 pandemic, what corrective measures can be taken to make the current curriculum capable of responding to any critical situation?

\section{Research context}

This research study was conducted in Pakistan's Balochistan province, the largest province in the country (occupying $44 \%$ of the area), with the smallest population (5\%). Balochistan is home to 10 million people. The province borders Iran in the west, Afghanistan and the Khyber Pakhtunkhwa province to the north, and the Punjab and Sindh provinces to the east. The Arabian Sea borders its south. Balochistan has 32 districts, and Quetta is the capital city. Quetta is also the largest city in the province, and its only metropolis, with a multi-ethnic and multi-lingual population. The rest of the province has small cities with mostly rural features. In addition to its three major languages (i.e., Balochi, Pashto, and Brohi), the minority languages of Balochistan include Hazargi, Saraiki, Sindhi, Punjabi, and Hindku. Urdu, the national language of Pakistan, is spoken and understood by most

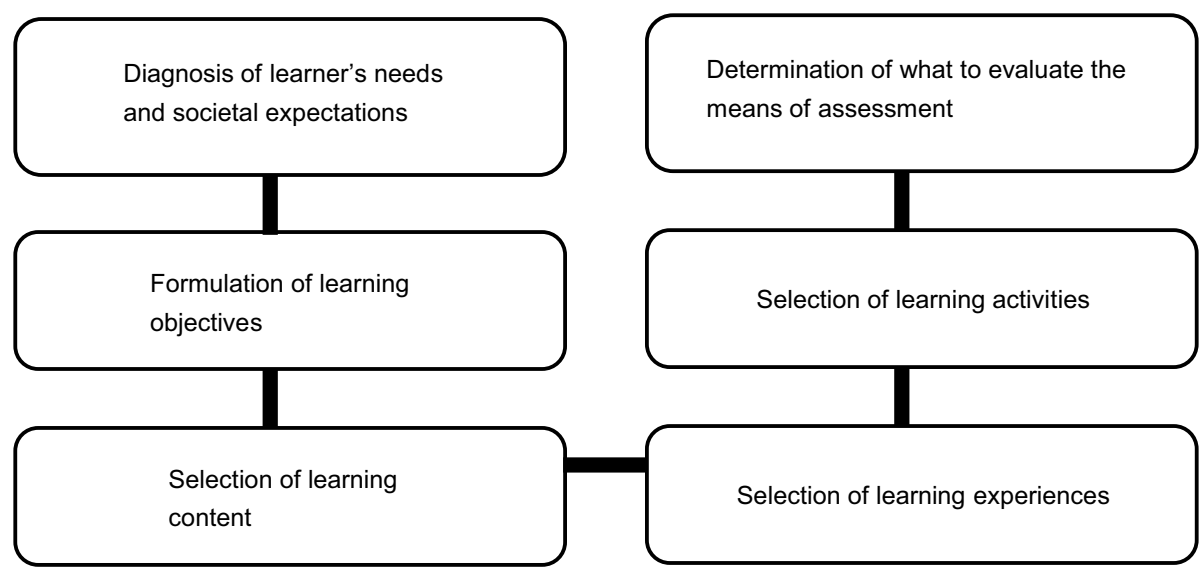

Figure 1 Major steps followed during the curriculum development process 
people and serves as the major vehicle of oral communication between speakers of the various native languages of Pakistan.

Pakistan has many minority ethnic groups in addition to the two major ethnicities of Baloch and Pashtun. Most of the minority ethnic groups live in Quetta. Other districts are roughly counted as either Baloch or Pashtun territory. The culture is primarily tribal, with deeply patriarchal and conservative roots. Most of the population is Muslim. However, some follow other religions, such as Hinduism, Christianity, and Sikhism.

The curriculum in Pakistan was previously developed at a central level, whereas textbooks were created at the provincial level. A recent constitutional amendment (the 18th Constitutional Amendment of 2010) relegated education to the provinces; however, the central government has continued to develop curriculum at the central level to ensure national cohesion and uniformity. This new curriculum has been termed the Single National Curriculum. Its centralized approach poses challenges to the curriculum's responsiveness to the needs and realities of the provincial context of Balochistan.

\section{Theoretical perspectives}

Moore (2015, p. 2) asserted that "we understand ourselves as social, cultural, ethical being in a world whose future is increasingly uncertain and difficult to predict". This assertion highlights the uncertainty and unpredictability of future events. Therefore, curriculum must be constructed to be responsive to uncertain and difficult situations. Moore alluded to the current system of education that predominately relies on indoctrination and thus hinders innovation and the dissemination of alternative modalities of education. Radical, global curricular change is likely to require a "long revolution" (Williams 1961) rather than an overnight coup; however, sometimes emergency situations invite curriculum workers to figure out alternatives in the absence of organized learning schools. Moore discussed Lawton's (2000, pp. 32-35) five proposals regarding the reorganization of curriculum:

1. from content and objectives to skills and processes;

2. from subjects and cognitive attainment to cross-curricular themes and the affective domain;

3. from didactic teaching to self-directed learning;

4. from academic or vocational to the integration of both aspects of experience;

5. from a national curriculum for 5-16 to lifelong learning.

The first proposal promotes the incorporation of skills into the curriculum, as well as a focus on processes. Skills and the learning of concepts and ideas can be related to Vygotsky's (1978) sociocultural theories and can also be associated with Lave and Wenger (1991), whereby students learn in a specific learning environment with support from teachers as mentors. Similarly, off-school time can be used if structured cognition is juxtaposed with cross-curricular themes and the affective domain. The third domain specifically relates to situations such as the Covid-19 pandemic. If the curriculum is developed to promote self-directed learning, learning will never cease. Similar to Young's (1998) concept of integrating vocational and academic experiences, the fourth proposal draws attention to the curriculum's focus in this direction. The fifth proposal points to lifelong learning, which recommends flexibility instead of controlled knowledge distribution. 
Building on Lawton (2000), Moore (2015, pp. 164-165) proposed the following characteristics for a curriculum of the future:

- forward-looking and proactive (in addition to paying full attention to the present and valuing the past);

- both respons-ive and respons-ible in their orientation (responsive to wider social and physical change and responsible in encouraging students to envision and to wish, knowing how to contribute to the creation of a safer, more equitable future);

- prioritising individual and collaborative problem-solving skills, "useful knowledge", and the promotion of love and capacity for learning; for investigation of self-expression over "knowledge for knowledge's sake" within active, student-centered classrooms;

- taking a more deliberate and thought-out ethical stance regarding concerns and issues that are global rather than local or national;

- ensuring that education-learning - is both relevant (to society and to the learner) and enjoyable;

- providing the stability that schools and teachers need while at the same time continuing to evolve and self-evaluate;

- seeking as far as possible to base judgements on curriculum inclusions and exclusions, on educational and social principles rather than on political ideology or educational myths or illusions of objectivity;

- promoting both collective, communitarian values and the development of the individual citizen as a happy, creative, well rounded, and culturally enriched human being.

These broad aims provide a framework for developers to mold the curriculum to be responsive to physical and social changes. Our attention is directed to both individual problem solving and collaborative work. These may be possible in virtual-classroom situations.

Moore (2015) further posed certain questions to guide the development of a responsive curriculum:

- What might a school curriculum look like if we decided to reject sameness as the dominant discourse in favour of difference, and if we rejected orderliness in favour of dealing with a certain amount of disorderliness - of recognising uncertainty, perhaps, and learning how to live with it rather than hoping or pretending it wasn't there?

- What if we listened more attentively and respectfully to the voices of young learners and their own articulations of their needs?

- What if we envisioned, in line with Bates' suggestion (Bates 2008, p. 98), a curriculum that set out to serve the interests of "the working class, women, ethnic minorities, etc.", and in doing so perhaps considered how "the insurrection of subjugated knowledge [might] be made a part of the curriculum of schools"?

- What if we predefined our curriculum in some alternative way, calling it, for exampleand fashioning it accordingly - the Critical Curriculum, or the Democratic Curriculum, or (to hark back to a previous chapter) the Global Curriculum, or the Activity Based Curriculum, or (in a reminder of the tyranny of The Answer) the Inquisitive or Questioning Curriculum?

- What if, after Atkinson (2013, p. 19), we structured our curriculum on Deleuze's "notion of immanence, where learning emerges from within the contingencies, differences and diversity of individual life", in which we focused our attention "not with a pre-ordained subjectivity but with a subject-yet to-come" transforming our and our students" conception of the world "from something given, that is to say 
already grounded in established knowledge, to something to be explored and continuously created not in terms of what exists but more in terms of what this world is capable of"?

Moore (2015) drew upon the concepts of Stenhouse (1975, pp. 86-87) with respect to how the curriculum should respond to students' needs. Stenhouse said, "one activity is more worthwhile than another if:

1. It permits children to make informed choices in carrying out the activity to reflect on the consequences of their choices.

2. It assigns to students' active roles in the learning situation rather than passive ones.

3. It asks students to inquire into ideas, applications of intellectual processes, or current problems, either personal or social.

4. It involves children with realia (i.e., actual objects, materials, and artifacts).

5. Completion of the activity may be accomplished by children at several levels of ability.

6. It asks students to examine a new setting idea, an application of an intellectual process, or a current problem that has been previously studied.

7. It requires students to examine topics or issues that citizens in our society rarely examine, which are typically ignored by the nation's major communication media.

8. It involves students and faculty members in "risk" taking—not a risk of life or limb but a risk of success or failure.

9. It requires students to rewrite, rehearse, and polish their initial efforts.

10. It involves students in the application and mastery of meaningful rules, standards, or disciplines.

11. It gives students a chance to share the planning, the carrying out a plan, or the activity results with others.

12. It applies to the expressed purposes of the students".

\section{Responsive curriculum}

Curriculum has been planned to direct learning experiences and intended outcomes for students' ongoing and active learning through the development of personal-social skills, by means of the structured rebuilding of knowledge and expertise, under the aegis of their schools (Zimu-Biyela 2019). Fomunyam (2014) argued that curriculum is a series of potentially disciplining and thinking experiences organized in a school. A responsive curriculum addresses students' changing intellectual and workplace requirements by, on the one hand, breaking down the gap between theories and universal knowledge, and on the other hand, adapting to the context of real-life situations. To be successful, learning experiences must fulfill students' needs and those of their community.

Moll (2004) argued that the capacity to respond to societal circumstances reflects the quality of the curriculum taught at schools and universities. This means that a specific program or curriculum is not merely about what is happening in the classroom but also about what a student has learned to do. Curricular responsiveness tackles employability (i.e., economic responsiveness), cultural responsiveness (i.e., a form of underlying awareness), and pedagogical or learning responsiveness within a discipline or a disciplinary capacity. 


\section{Conceptualization of a responsive curriculum}

Curriculum can be conceptualized from different points of view. From the traditional perspective, it is viewed as a program of planned course activities for a subject, and their intended learning outcomes (Schubert 1986), whereby the focus is directed at the content of the curriculum, with very little attention to teaching and learning (Tanner 2007). According to the progressive perspective, as articulated by Tanner, curriculum can be reconceived through the reconstruction of knowledge, thoughts, and modes of guided experiences, thereby enabling learners to gain intellectual mastery over the course of successive educational experiences.

This ensures that the curriculum prepares students for future scenarios they may not encounter at school. Schubert (1986) echoed that curricular activities must adapt to specific contexts; curriculum should always be rebuilt to fit changing circumstances. Similarly, Peters (2000) emphasized that a curriculum should not be made uniform and long term; rather, it must be linked to individual requirements, the challenges confronting practitioners, and expected future trends.

In this article, we use the term responsive curriculum to refer to an adaptive course of studies that, on one end, bridges the gap between abstract educational theories, universal knowledge, and learning, and on the other, connects the more contextually demanding realities of changing situations with the world of work.

The literature on responsive curriculum has highlighted various requirements to respond to the changing needs of students; these include interdisciplinarity (Alexander 2011) and emphasis on teaching and learning that are based on problem areas (Kiguli et al. 2011). It also stressed the importance of developing students' competencies required to perform tasks in real-life situations (Kouwenhoven 2009); the need to involve teachers, students, and society in the development of the curriculum, as well as the centrality of faculty and the need for expert support in the curriculum development process (Taylor 2000).

\section{Attributes of a responsive curriculum}

A list of the attributes of a responsive curriculum explicitly demonstrates that a process that can guarantee the curriculum will fulfill students' intellectual needs in emergencies is rare, especially in Balochistan. Therefore, we hope that this study will fill a gap in the literature. With the aid of the literature on conceptualization (discussed in the previous section), we have established some specific attributes of a responsive curriculum creation process. These attributes are related to the design process, implementation process, and evaluation process of the curriculum. Some of the major attributes are described in the following sections.

\section{Aims, goals, and objectives of the curriculum}

Manathunga (2011) described aims and goals as a basic attribute of a responsive curriculum. With such a teaching and learning approach, students and teachers are encouraged to understand and describe the curriculum in a manner that makes it aims, goals, and objectives clear. Extensive discussion and reflection can clarify curricular content and delivery methods (Wolf 2007) for desired learning goals and learning outcomes (McFadden et al. 2011). 


\section{Curriculum is inclusive}

An inclusive curriculum expects, respects, and acknowledges all students' access and involvement in study. Villegas and Lucas (2002) mentioned that a responsive curriculum is always inclusive because it meets the different needs, experiences, preferences, and unique characteristics of all students and ensures that every student is involved in the learning process. This helps the teachers accept students with all abilities and promote positive attitudes among students from diverse cultural backgrounds.

\section{Curriculum responds to the needs of students, parents, and society}

A responsive curriculum adapts to the learning needs of students and the expectations of parents and society by presenting content in a simple, comprehensible manner and by ensuring that students and parents can access and assess it in ways they understand (Moll 2004; Sarason 2009; DHET 2012; Hayes and Juárez 2012). This means that course content reflects the connection between students' learning needs and society's changing circumstances. To achieve this, content must allow flexibility in case assignments, bring real-life examples into the learning context, and include role playing or immersive games. Boughey (2009) stated that a responsive curriculum has the ability to teach and train students to meet their own needs for growth, to grow in ways that meet society's changing needs, and to be able to contribute their best to society accordingly.

\section{Curriculum is intellectually and emotionally stimulating}

According to Biggs (2003), two important steps are necessary for the effective use of material (curricular). First is students' level of perception and methods for getting new knowledge beyond their own existing (intellectual) understanding; second is students' awareness of their experiences (emotional). The extent to which the curriculum covers both these aspects reflects its responsiveness. This attribute sets the framework, and participants' views were collected accordingly by the researchers.

\section{Curriculum optimizes students' learning potential}

Learning optimization is best defined as the activities that encourage students to simultaneously think, evaluate, question critically, and acquire factual knowledge (Biggs 2003). In the context of this study, the researchers view learning optimization as "engaging students in activities that involve learning through other skills beyond listening and reading" (p. 15). A responsive curriculum promotes student-teacher interaction, develops students' higher-level cognitive skills, and promotes active learning by enhancing students' potential to work both collaboratively and independently. The major goal of such a responsive curriculum is to create autonomous and self-directed learners (McKinney 2009; Phan and Deo 2007).

\section{Curriculum support for e-learning / distance learning}

Designing a curriculum for distance-learning programs is distinct from designing internal or face-to-face learning, due to the fact that the needs of distance learners are quite different from those of learners using other modes of study. Smaldino and Simonson (1999) held that in the process of curriculum design, the learners, their specific learning needs, and the medium of instruction through which such learning takes place should be the top priority 
for curriculum experts. The focus should be on "what is needed to improve performance". This implies the satisfactory condition of "what is actually happening?", "how do the students feel about e-learning / distance learning?", and "what are the alternate modalities?". Smaldino and Simonson also emphasized a few other elements of a responsive curriculum that need consideration while designing any distance learning course. These include "the course contents, the teaching strategies, and assessment techniques". A well-crafted responsive curriculum has meaning. Moreover, assignments are supported with strong instructional and assessment approaches.

Although the curriculum development literature offers valuable information regarding a responsive curriculum for emergencies situations, few studies provide an empirical overview of the methods used to implement such a curriculum in practice (Cunha et al. 2000; Kiguli-Malwadde et al. 2006; McFadden et al. 2011; Paulsen and Peseau 1992). Moreover, no such study has been conducted in Pakistan, much less in the context of Balochistan (as per the researchers' knowledge). Balochistan, where students are studying in schools, colleges, and universities, has been victimized for years due to historical events, such as devastating earthquakes and the global war on terrorism (for the last two decades). There is a crucial need for in-depth studies on the existing curriculum and the initiation of a responsive curriculum that can cope with any emergency (Gul and Khilji 2020). It is widely said that "tragedy teaches lessons", but lessons can only be learned if the victims identify the causes, create appropriate mechanisms, and devise plans to prevent or mitigate them in the future. Tragedies and pandemics not only ravage life but also show the extent to which the respective communities/countries and their institutions are vulnerable and unable to act. Moreover, if the affected countries, areas, or communities do not have adequate plans and effective systems in place to contribute to robust catastrophe preparedness, recovery, and response programs, such disasters leave behind long-term impacts.

\section{Research methodology}

\section{Participants and data collection procedure}

This study is qualitative in nature. Qualitative research is used to discover the fundamental reasons, beliefs, and motives underlying a phenomenon. This method offers insights into research phenomena and establishes ideas or theories pertaining to future quantitative analysis work. Creswell (2009) pointed out that researchers who use qualitative approaches dive into situations and are vital resources for collecting data, often informed by knowledge and opinions.

As per the Carnegie Classifications, we used purposive sampling to ensure the diversity of institutional types and geographic locations within the sample. The criteria for participation was that individuals must know the curriculum or be experienced in the curriculum development process and provide detailed generalizable information. The purposeful sample for this study comprised 10 experts selected from the Bureau of Curriculum, in Balochistan, with wide working experience in the same field, as well as 20 school principals and 35 teachers with vast teaching experience in different districts of Balochistan. The principals were engaged in teaching practices; therefore, their responses were recorded as teachers.

With respect to academic qualifications, most respondents held MS/MPhil or MA/MSC degrees (Table 1). Similarly, with respect to professional qualifications, most respondents $(n=58)$ held MEd degrees. Some respondents $(n=07)$ held BEd degrees. In term of 
teaching experience, the greatest number of study respondents $(n=27)$ had 11 to 15 years of experience and $(n=23)$ had 5 to 10 years of experience.

A content analysis of Pakistan's existing National Curriculum Framework (Ministry of Federal Education and Professional Training 2018) was carried out to explore the research questions. Then semi-structured interviews were conducted to obtain a more in-depth overview of the participants' curriculum responsiveness during this pandemic, as well as the corrective measures for making the curriculum adequate enough to respond to any emergency. The basic attributes of a responsive curriculum, with respect to students' learning during the Covid-19 pandemic, included (a) clarity in the purpose of the curriculum, (b) inclusiveness of the curriculum, (c) intellectual and emotional stimulation of students' learning, (d) responsiveness of the curriculum to the needs of students and parents, and (e) curricular support for e-learning / distance learning. These were identified in the existing literature and coded for further analysis / pattern detection that informs the research question.

\section{Data analysis}

To ensure trustworthiness, ethnographic content analysis was conducted on the National Curriculum Framework (Ministry of Federal Education and Professional Training 2018). Ethnographic content analysis refers to a method of retrieving and analyzing documents for their significance and meaning in context (Elo et al. 2014). The emphasis is on a description, the search for context, explanatory meanings, patterns, and processes (Grbich 2013). The National Curriculum Framework is a lengthy document; therefore, due to time constraints, the focus was on the basic components of the curriculum development process and the guiding principles.

The collected data were analyzed using the thematic analysis model (Braun and Clarke 2006). According to Braun and Clarke, thematic analysis is "a tool to find, analyze and report trends within the data" (p. 79). In this thematic analysis, the researchers applied the six-step method suggested by Braun and Clarke (2006). Data were evaluated using all these six stages: familiarity, coding, generation, searching themes, naming and defining themes, and final reporting. Using this structure, with its consistency and practicality, constitutes an effective and powerful approach to conducting social science research that helps the researcher avoid obstacles during the study.

Using thematic analysis, we read, organized, and classified participants' comments, and the segments relevant to research questions were coded. After this stage was completed, an internal audit was conducted in which two sets of codes were compared to validate the data. One set of themes were established. Each theme's essence was interpreted in detail, and total code counts were generated by counting each time participants' comments corresponded with a theme.

Table 1 Demographic information on respondents

\begin{tabular}{lllrlrrr}
\hline Designation & F & $\begin{array}{l}\text { Highest academic } \\
\text { qualification }\end{array}$ & F & $\begin{array}{l}\text { Highest profes- } \\
\text { sional qualification }\end{array}$ & F & $\begin{array}{l}\text { Experience, } \\
\text { in years }\end{array}$ & F \\
\hline Principal & 20 & MS/MPhil & 8 & MEd & 58 & $5-10$ & 23 \\
SST & 35 & MA/MSC & 50 & BEd & 7 & $11-15$ & 27 \\
SS(BOC) & 10 & BA/BSC/BS & 7 & & & $16-20$ & 7 \\
& & & & & $21-25$ & 8 \\
\hline
\end{tabular}




\section{Content analysis of Pakistan's National Curriculum Framework (2018)}

The curriculum framework is a document focused on national policy papers, such as Pakistan's Constitution, national education policy, and Vision 2025. Such a framework includes mechanisms, time frames, curriculum development, reviews, and other related schoollearning issues. It sets out fundamental principles for curricula, abilities, beliefs, and roles that students in the major fields of training are required to master at each level in order to achieve target outcomes. It also provides broad curriculum policy guidelines for designing the subject curricula, training systems, evaluations, and assessments of students' achievement and teachers' professional development.

The National Curriculum Framework of Pakistan was planned in 2018. This was the first-ever curriculum framework in Pakistan's educational history. Earlier, the curriculum in Pakistan was regulated through subject-specific curricular guidelines. The new framework was launched as a guardian document to instill patriotism, safeguard national ideology, and promote national harmony in order to counter education's devolution to the provinces and federating units, which were established by the 18th Constitutional Amendment of 2010. The 18th Constitutional Amendment made curriculum development and implementation a provincial responsibility. However, more recently, the central authorities have shifted curriculum development back to the national level. All the provinces agreed on the curriculum framework, which allows for broader national harmony and interest guidelines from the central authorities and delegates curriculum development to the provinces.

The provinces appreciated the devolution of curriculum development to the provinces, because they believe the curriculum's provincial focus, being context responsive, will be more educational for children. However, the National Curriculum Framework (Ministry of Federal Education and Professional Training (2018, p. 8) stated:

After the 18th Constitutional Amendment, the devolution of curriculum and standards has created several issues and challenges which need to be addressed urgently. Some key challenges are:

1. Safeguarding and promoting the ideology of Pakistan;

2. Ensuring integrity, solidarity, and national cohesion;

3. Developing and maintaining uniform standards in learning and assessment;

4. $\quad$ Ensuring uniformity in diversity;

5. Honoring national and international commitments;

6. Implementing Article 25A-Right to Education;

7. Coordination, linkages, and harmonization;

8. Equal access and opportunities to learners.

Thus, the top-down curricular approach leaves less latitude for contextual realities. This approach also neglects the cognitive and psychological needs of learners. The framework gives predetermined curricular mandates that require the provincial education authorities to achieve educational goals that were set at the central level.

The framework highlights the curricular goals of Pakistani society. It vows to safeguard regional languages and pledges to promote unity among diverse cultural outlooks. For this purpose, educators believe the curriculum should be planned and controlled by the central authorities.

The framework offers detailed guidelines on the steps of curriculum development, based on Taba's (1962) model. It states that curriculum development should start with 
the diagnosis of learners' needs. Similarly, guidelines are provided to set learning objectives, select content and learning activities, and devise assessment methods. However, the framework ignores the realities and contexts of the schools. The guidelines given in the framework seem to be for the enactment of an ideal curriculum, whereas the expectations of the curriculum have not been matched with the school context. According to the Balochistan Education Department (Government of Balochistan 2018), 50\% of primary schools have only one teacher to teach six grades. Additionally, 20\% of primary schools have only two teachers available. Similarly, most schools lack basic facilities, such as water, electricity, and boundary walls. Most of the teachers are not prepared to use modern techniques of teaching. The framework is silent regarding the autonomy of teachers and the selfdirected learning of students. It also does not provide guidelines on learning in the time of emergencies.

\section{Thematic analysis of the interviews}

The content analysis of the National Curriculum Framework was followed by a thematic analysis of the individual interviews with teachers, school principals, and curriculum experts. The study participants highlighted that the National Curriculum Framework was developed at the central level, without researching the regional contexts, although the provincial representatives took part in the development process. Consequently, the framework seems to be less responsive to the regional contexts.

The interview data were collected using an individual interview protocol, via phone, following standard operating procedures due to the Covid-19 pandemic. The data were analyzed using thematic analysis (Braun and Clarke 2006). The following themes emerged from the analysis.

\section{Clarity of the aims, goals, and objectives of the curriculum}

During this study, most participants agreed that the aims, goals, and objectives of the curriculum content were not clear. They suggested that the curriculum be flexible and have an apparent purpose, and that its development process (i.e., including the purpose of the learning material and course outcomes) should be transparent. Moreover, these outcomes should be structured. One of the curriculum experts alluded to this by stating,

The curriculum is to provide a guideline to the content and to what a course entails.

The purpose of the curriculum should also be transparent to the needs of the industry and the country. This improves the quality of student education.

This statement shows that the curriculum is rigid in nature and controlled, with no flexibility for curricular material, such as textbooks, which are generally developed at the provincial level.

Another curriculum expert pointed out that "the curriculum does not support alternative modalities for students' learning continuity". This observation reflects the current Covid19 situation, which left students helpless upon closure of the schools. The curriculum, according to the participants, does not have opportunities for independent learning.

The participants further stated that recommendations for textbooks appropriate for students' age and grade levels are not clear. Additionally, the exercises within textbooks are not consistent with assessment practices, which should adhere to independent practices, as 
outlined in the national curriculum standards. Accordingly, some SLOs are not included in the textbooks, although they may be addressed through classroom activities or assessment questions not mentioned in the textbooks.

\section{Curriculum inclusiveness}

Participants showed disappointment about curriculum inclusiveness during the emergency situation of the Covid-19 pandemic. They stated that the curriculum was not inclusive. Inclusiveness requires that curricular guidelines be specific about outcomes and address challenges in practice. Inclusiveness should relate to other environments and be associated with other disciplines in the real world. Some of the teachers and school principals mentioned that they felt the content was outdated and did not support students during this emergency situation. One stated, "Students are not supported enough because, in regular face-to-face classroom practices, little intellectual growth had been noticed last year, and strategies for the students with physical disabilities or slow learners are excluded". Teachers and school principals alike agreed with this statement. The school principals and teachers generally complained that the curriculum was divorced from the context and children's realities. This might be a result of the exclusion of teachers and school principals from the curriculum development process.

\section{Curriculum responsiveness to the needs of students, parents, and society}

The curriculum should be responsive to students' learning needs by teaching them in ways that are accessible and assessing them in ways they understand (Moll 2004; Sarason 2009; DHET 2012; Hayes and Juárez 2012).

One participant stated the curriculum was not responsive to the Covid-19 pandemic. She claimed,

A responsive curriculum ensures that the content speaks to students' needs and practices for students studying online from home. However, the curriculum in place does not have the potential to respond to either students' needs or pedagogic needs of the teachers.

Some of the participants stated that the curriculum was partially responsive: "Somehow the curriculum is responsive, but it needs to be changed". Additionally, they stated that the benchmark should be set to prepare students "studying anywhere, anytime" when emergency situations arise.

The teachers felt that the curriculum was not responsive because it did not address students' and parents' needs. The participants argued that the government needs to prepare parents so they can be responsible for their children learning at home, because most parents are uneducated. The participants highlighted the need for parents' involvement in their children's learning process. One pointed out, "The situation has convinced us that the relationship of school with parents must be redefined and revitalized". This gap was experienced by all participants: teachers, school principals, and curriculum experts.

The participants suggested parents should be prepared to engage their children in learning at home. This can be made easier with social media platforms that allow parents to supervise their children in times of emergencies, such as the Covid-19 pandemic. 


\section{Contextual responsiveness of the curriculum to local and global needs}

The school principals believed that the current curriculum has manifold deficiencies with respect to simultaneously responding to both local and global needs. However, this situation could be handled by local teachers who have been appointed at the village, tehsil, and district level.

At the local level, the teachers are in contact with parents and community members. They may prepare lessons and home-based assignments in order to remedy the disruption of studies. A participant commented, "The role of a local teacher is significant. They can help students sequentially by teaching them geography, history, culture, flora, and fauna of the vicinity. This would keep their learning context specific". It is an expression of Balochistan's culture that teachers living in the school locality have a close affinity with children and their parents. This allows them to interact with the children during off-school time. Thus, when situations such as the Covid-19 pandemic arise, the teachers can teach the children during off-school time. This can help the children remain connected with learning under the supervision of teachers. This also transcends conventional tunneled curricular approaches.

\section{Intellectual and emotional motivation of the curriculum}

The representative teachers stated that, in traditional classroom teaching, the contents of the curriculum are intellectually and emotionally stimulating to some extent; for example, a second chapter cannot be approached unless the first chapter has been taught. One teacher added, "The way the curriculum is structured helps us engage students with the curriculum, and we find it emotionally and intellectually stimulating because we are consistently thinking of ways to improve our students and keep them engaged with the content”. Nevertheless, this sequence may challenge students' capacity for independent learning.

The majority of the participants thought the present curriculum did not allow students to optimize their independent learning and did not support their ability to work in out-ofclassroom situations. One teacher pointed out, "In real, face-to-face teaching, we guide and encourage students' learning potential by motivating them in different ways". However, the majority of the students were not internally motivated to succeed in learning. The curriculum experts asserted that there was no opportunity for self-learning in the curriculum. This could be due to political influences on the curriculum not allowing for independent learning.

\section{Curriculum support for e-learning/distance learning}

Most of the participants (i.e., teachers, school principals, and curriculum experts) believed that online/e-learning and home-based learning could be alternative modalities for students to continue their education. However, all the mentioned modalities have pressing challenges. For example, some participants said they had not had electricity in their districts for the last two months. Others mentioned the limited electrical supply in some districts. These pose huge hurdles to the successful implementation of online/e-learning.

In addition to issues with accessibility, some participants highlighted that online/elearning is only feasible in the higher grades, where students can independently respond to the online lecture, screen sharing, and assignments. Students in the lower grades (i.e., the primary level) are unable to participate in online learning without a teacher's mentorship. 
The provincial education department has initiated a home-based schooling concept, called "My home is my school", that motivates parents to arrange for the continuity of their children's learning at home. In response to this initiative, one of the participants said,

Home-based schooling would be arduous because they can never be as organized as schools on time and space realities. The habitual organized way of a school must go through a huge shift from formal schooling to home-based schooling. The curriculum material organization would need huge efforts, which would be extremely difficult to ensure in the absence of an organized structural approach.

However, some participants spoke in favor of online/e-learning if the scope was limited to grades above the elementary level. The participants encouraged online/e-learning, with the condition that the issues of accessibility be resolved. One participant stated,

The online methods may help students for the continuity of their education in the Covid-19 situation, but there are heavy issues of access/support to online resources. For example, in our village district, Ziarat, we do not have electricity supply for three months.

The participants believed that online-e-learning would depend on two major factors: parents' educational level and the support system and facilities available at home. This means that online/e-learning has prerequisites before it can be implemented. The participants highlighted the critical issues of internet availability and connectivity.

\section{Curricular support for emergency situations}

The participants claimed that the curriculum was unprepared for dealing with emergency situations, such as the Covid-19 pandemic, particularly with respect to the elementary grades. One of the curriculum experts opined, "Our curriculum should be redesigned so that it is responsive to such events. Apart from Covid-19, we could confront more natural disasters, such as floods, earthquakes, and wars, which may cause closure of the schools".

The participants pointed out that some covert or inexplicit guidelines relating to such incidents might exist, but the curriculum itself was mostly silent. The participants highlighted that the Covid-19 pandemic was a test case for the schools to design a curriculum configured with digital learning sources. This may also make educators rethink or redefine the teacher's role in discovering alternative strategies for teaching and for facilitating students in case schools are temporarily closed. One of the participants claimed,

Our curriculum is not prepared for such incidents because our curriculum is predetermined and outcome based. The authorities harshly control it. The curriculum would have been responsive had it been somewhat flexible. The curriculum should be redesigned so that it produces analytical and critical souls.

The participants, as curriculum experts, were aware of the weaknesses of a predetermined and controlled curriculum. This predetermination snatches away teachers' autonomy and places them in the system as a mere distributor of knowledge. The participants recommended that some degree of autonomy be established for both teachers and students, to meet the needs of their contextual realities.

The qualitative analysis revealed that the participants were disappointed with the curriculum's responsiveness to situations such as the Covid-19 pandemic. However, they believed this situation has lessons for educators to ponder in redesigning the curriculum to support learning continuity in normal as well as challenging times. They expressed 
encouragement for incorporating online/e-learning in the curriculum, while simultaneously highlighting obstacles to overcome. The participants offered the following recommendations to ensure the curriculum is more responsive to learning in such situations:

1. Part of the curriculum must be self-explanatory, so students can engage with the learning material until the situation returns normal.

2. "Must-know" topics/themes in the curriculum should be identified. Special lessons can be prepared on the identified topics/themes and be shared with students through various channels: social media platforms, screen sharing, YouTube channels, and other methods. In this way, students' learning progression will not be disrupted.

3. Curriculum experts can identify must-know concepts and share them with educational authorities. The authorities should prepare teachers to develop lessons that can be shared with students.

4. A separate curriculum should be available for emergencies. This can be a specialized curriculum only for use in emergencies. Alternatively, a portion of the regular curriculum could be treated as an emergency curriculum, guiding students to learn during such situations.

5. The best way to respond to such situations is to equip students to be critical and analytical thinkers. This way, students, as future citizens, can deal with such challenges.

6. A separate subject area should be dedicated to health and hygiene, and specifically, should include precautionary measures to avoid pandemics, such as Covid-19.

7. Learning should not be limited to the written text. Alternative ways of educating children through social learning should be available.

8. Schools should remain open; any loss of teaching time can be compensated through a condensed curriculum or curriculum mapping to identify and teach the most significant themes/concepts, skills, and behavior.

9. The curriculum should include learning material designed for self-directed learning, particularly at lower grade levels and in the social sciences.

10. A teacher guide on natural and human-made disasters should be prepared as part of teachers' professional learning.

11. School head teachers can play a significant role in improving this situation by inviting teachers to schools in shifts. Head teachers/principals can direct teachers to map their course content so it can be taught weekly, as needed in the current situation.

12. Teachers can play a pivotal role in being aware of the realities of the local context. They can immerse themselves in creating opportunities for children so the children can continue learning.

13. Currently, teachers are posted at the village level. Therefore, they can arrange to aid students in their studies. However, this requires a staunch commitment from the topdown educational hierarchy. Directives can be issued to cluster heads to assign responsibilities to teachers for their individual cluster.

14. The entire curriculum does not need to be taught. Some subjects can be mapped. For example, subjects that are appropriate for independent learning can be left out. Science, English, and Mathematics can be the focus of the curriculum.

15. Teachers need to be incentivized. This can be done by giving them additional money to motivate their participation.

16. Another alternative is telecasting prepared lessons through TV and radio channels.

17. When a course is designed for emergency situations, an assessment also needs to be designed for that course. 
18. Must-know topics should be identified for both instruction and assessment. Primarylevel classes do not need assessment.

19. It is hoped that arranging possible ways to ensure students' learning continuity will bring about at least a $10 \%$ improvement. We believe something is better than nothing. We expect the multiplication effect of forming a healthy culture to challenge the multiplication effect of the Covid-19 pandemic.

20. Teachers should be given reasonable autonomy, even in normal situations. However, for teachers to have autonomy, they must be supported with financial benefits and professional development.

21. The curriculum should permit the adoption of a creative approach. The alignment between society and curriculum should be clear.

22. Different stakeholders (e.g., lecturers, industry, society, students, and heads of departments) should be part of the curriculum development process.

\section{Discussion and conclusions}

We conducted this study in the Balochistan province of Pakistan. Balochistan is area-wise the largest and population-wise the smallest province of Pakistan. Additionally, it is the poorest province of the country. There has been a tussle between the central authorities and the provinces over control of Pakistan's curriculum matters for the last few years. The school closures due to the Covid-19 pandemic occurred amid these circumstances. The tussle is still going on; however, we focused on how responsive the curriculum in Pakistan is to situations such as the Covid-19 pandemic, irrespective of whether the curriculum is constructed at the national or the provincial level.

The participants in the study were curriculum experts, teachers, and school principals. They showed their disappointment with the curriculum's responsiveness to situations such as the Covid-19 pandemic. They believed that the top-down approach and predetermined nature of the curriculum make it difficult to respond to such a situation. They thought the curriculum was highly rigid, not allowing for alternative modalities. Their ideas regarding the curriculum in Pakistan synchronize with the banking concept of Freire (1973). This finding contradicts the theoretical perspective promoted by Moore (2015), who envisioned a more flexible curriculum that is responsive to learners' needs and allows for pedagogical readjustments.

The participants noted a distrust of the educational system by teachers. Teachers in Pakistan, according to the participants, should be more than the distributors of official knowledge. They also highlighted the low self-respect of teachers. A teacher is a person who enacts the curriculum. Teachers give life to the curriculum. However, their very identity as a teacher has not been recognized in society. Identity is the most important dimension in human life (Bracher 2006). Therefore, the participants suggested the whole curriculum be redesigned to make it responsive to emergencies such as the Covid-19 pandemic. Bertram (2006), and Moll (2004) also suggested the need for a heightened responsiveness of the curriculum to students' as well as society's needs and interests. The curriculum framework serves as an empty structure that is impotent to cope with this type of situation.

We draw attention to the challenge of teachers' low autonomy in both curricular matters and pedagogical aspects, in contrast with the demand by curriculum theorists for more power for teachers. The reconceptualized curriculum theorists (Grundy 1987; Pinar et al. 1995) challenged the narrow description of curriculum; they consider curriculum a process 
instead of a product. This notion allows the curriculum to encompass learning in both offschool and in-school contexts.

The study has limitations due to the lockdown situation in Pakistan. Ideally, focus group interviews should have been conducted to supplement the thorough review of all relevant documents related to Pakistan's curriculum. Nevertheless, the findings offer a representative picture of curriculum in Pakistan. The participants explicitly shared that the current curriculum is nonresponsive to emergencies. Moreover, they believed the curriculum to be unsupportive of children's learning even during normal times. As a remedy to this issue, they suggested the curriculum be completely revamped in line with the extensive findings of research studies. They further suggested that teachers be properly financially compensated and professionally developed before they can be expected to produce improved educational outcomes. They recommended the development of curricular material that is current, context specific, and supportive of independent learning.

We believe that, by presenting the perspectives of curriculum experts, teachers, and principals who face the on-ground realities of the existing curriculum's positive and negative aspects, this study's findings provide a foundation for developing and improving the existing school curriculum. The findings also suggest ways to design a responsive curriculum that can fulfill the students' requirements as well as those of society in emergency situations. As Schubert (1986) pointed out, "Since curriculum activities are necessary for specific contexts, a curriculum is always created and reconstructed to meet changing conditions". Likewise, Peters (2000) stressed that a curriculum should be long term, consistent, and adaptable to emergent needs.

\section{References}

Alexander, S. T. (2011). Culture, efficacy and outcome expectancy in teacher preparation: How do the beliefs of pre-service interns, mentor teachers, university supervisors and teacher educators compare? Cleveland, $\mathrm{OH}$ : Cleveland State University.

Atkinson, D. (2013). The blindness of education to the 'untimeliness' of real learning. London: School of Social Science and Public Policy, Kings College London.

Bates, M. (2008). Work-integrated curricula in university programs. Higher Education Research \& Development, 27(4), 305-317.

Bertram, C. (2006). Knowledge, pedagogy and assessment in the old and new further education and training history curriculum documents. Education as Change, 10(2), 33-51.

Biggs, J. B. (2003). Teaching for quality learning at university (2nd ed.). Buckingham: SRHE and Open University Press.

Bracher, M. (2006). Radical pedagogy: Identity, generativity, and social transformation. Dordrecht: Springer.

Braun, V., \& Clarke, V. (2006). Using thematic analysis in psychology. Qualitative Research in Psychology, $3(2), 77-101$.

Boughey, C. (2009). Higher education in South Africa: Context, mission and legislation. In S. Gravett, \& H. Geyser (Eds.), Teaching and learning in higher education. Pretoria: Van Schaik.

Creswell, J. W. (2009). Research design: Qualitative and mixed methods approach. Thousand Oaks, CA: Sage.

Cunha, Z. D., Contento, I. R., \& Morin, K. (2000). A case study of a curriculum development process in nutrition education using empowerment as organizational policy. Ecology of Food and Nutrition, $39(6), 417-435$.

DHET [Department of Higher Education and Training] (2012). Draft policy framework for the provision of distance education in South African universities. Pretoria: DHET.

Elo, S., Kääriäinen, M., Kanste, O., Pölkki, T., Utriainen, K., \& Kyngäs, H. (2014). Qualitative content analysis: A focus on trustworthiness. SAGE Open. https://doi.org/10.1177/2158244014522633 
Fomunyam, K. G. (2014). Curriculum theorizing and individualism: An exploration of the curriculum's relation to the social, personal and political dimensions of schooling. Mevlana International Journal of Education, 4(2), 122-131.

Freire, P. (1973). Education for critical consciousness. New York, NY: Bloomsbury.

Government of Balochistan, Pakistan (2018). The Balochistan Education Management Information System (BEMIS). Balochistan: Policy Planning and Implementation Unit (PPIU). Balochistan: Education Department, Government of Balochistan.

Grbich, C. (2013). Qualitative data analysis: An introduction. London: Sage.

Grundy, S. (1987). Curriculum: Product or praxis? London: Falmer Press.

Gul, R., \& Khilji, G. (2020). Challenges and possibilities to online education amid Covid-19 outbreak in Balochistan, Pakistan. Unpublished manuscript.

Hayes, C., \& Juárez, B. (2012). There is no culturally responsive teaching spoken here: A critical race perspective. Democracy and Education, 20(1), 1.

Kiguli-Malwadde, E., Kijjambu, S., Kiguli, S., Galukande, M., Mwanika, A., Luboga, S., \& Sewankambo, N. (2006). Problem-based learning, curriculum development and change process at Faculty of Medicine, Makerere University Uganda. African Health Sciences, 6(2), 127-130.

Kiguli, S., Baingana, R., Paina, L., Mafigiri, D., Groves, S., Katende, G., et al. (2011). Situational analysis of teaching and learning of medicine and nursing students at Makerere University College of Health Sciences. BMC International Health and Human Rights, 11(S1), S3.

Kouwenhoven, W. (2009). Competence-based curriculum development in higher education: A globalised concept? Technology Education and Development, 8(2), 1-22.

Lave, J., \& Wenger, E. (1991). Situated learning: Legitimate peripheral participation. Cambridge: Cambridge University Press.

Lawton, D. (2000). Values and education: A curriculum for the twenty-first century. In J. Cairns, R. Gardner, \& D. Lawton (Eds.), Values and the curriculum (pp. 25-36). London: Routledge.

Manathunga, C. (2011). Enhancing a culturally and socially responsive curriculum. Brisbane: QUT Teaching and Learning Unit.

McFadden, K. L., Chen, S.-J.G., Munroe, D. J., Naftzger, J. R., \& Selinger, E. M. (2011). Creating an innovative interdisciplinary graduate certificate program. Innovative Higher Education, 36(3), $161-176$.

McKinney, C. (2009). IALEI country report multicultural education in South Africa. Cape Town: University of Cape Town. http://www.intlalliance.org/fileadmin/user_upload/documents/Conference _2010/NPSA.pdf.

Ministry of Federal Education and Professional Training (2018). National curriculum framework Pakistan. Islamabad: Government of Pakistan.

Moll, I. (2004). Curriculum responsiveness: The anatomy of a concept. In H. Griesel (Ed.), Curriculum responsiveness: Case studies in higher education (pp. 1-19). Pretoria: South African Universities Vice-Chancellors Association (SAUVCA).

Moore, A. (2015). Understanding the school curriculum: Theory, politics and principles. New York, NY: Routledge.

Paulsen, M. B., \& Peseau, B. A. (1992). A practical guide to zero-based curriculum review. Innovative Higher Education, 16(3), 211-221.

Peters, M. (2000). Does constructivist epistemology have a place in nurse education? Journal of Nursing Education, 39(4), 166-172.

Phan, H. P., \& Deo, B. (2007). The revised learning process questionnaire: A validation of a Western model of students' study approaches to the South Pacific context, using confirmatory factor analysis. British Journal of Educational Psychology, 77, 719-739.

Pinar. W. F. (2020). Call for submissions: Special issue of Prospects on Curricular Responsiveness to Crisis. https://www.springer.com/journal/11125/updates/17890172.

Pinar, W. F., Reynolds, W. M., Slattery, P., \& Taubman, P. M. (1995). Understanding curriculum: An introduction to the study of historical and contemporary curriculum discourses. New York, NY: Peter Lang.

Rahman, A. (2020, February 5). Education emergency. The News. https://www.thenews.com.pk/print /609009-education-emergency.

Sarason, S. B. (2009). American psychology and schools: A critique. New York, NY: Teachers College Press.

Schubert, W. H. (1986). Curriculum: Perspective, paradigm, and possibility. Boston, MA: Allyn and Bacon. 
Smaldino, S., \& Simonson, M. (1999). Instructional design for distance education. Paper presented at the National Convention of the Association for Educational Communications and Technology, February 10-14, Houston, TX. https://files.eric.ed.gov/fulltext/ED436149.pdf.

Stenhouse, L. (1975). An introduction to curriculum research and development. London: Heinemann.

Taba, H. (1962). Curriculum development: Theory and practice. New York, NY: Harcourt.

Tanner, C. A. (2007). The curriculum revolution revisited. Journal of Nursing Education, 46(2), 12-21.

Taylor, P. (2000). Improving forestry education through participatory curriculum development: A case study from Vietnam. The Journal of Agricultural Education and Extension, 7(2), 93-104.

Ullah, H. (2020). Covid-19 and education: Unequal learning loss. Pakistan Today. https://www.pakistanto day.com.pk/2020/05/07/covid-19-education-unequal-learning-loss/.

Vigotsky, L. S. (1978). Mind in society: The development of higher psychological processes. Cambridge, MA: Harvard University Press.

Villegas, A. M., \& Lucas, T. (2002). Preparing culturally responsive teachers: Rethinking the curriculum. Journal of Teacher Education, 53(1), 20-32.

Williams, R. (1961). The long revolution. London: Chatto and Windus.

Wolf, P. (2007). Curriculum development in higher education: A faculty-driven, data-informed, and educational developer-supported approach. New Directions for Teaching and Learning, 2007(112), 15-20.

Young, M. (1998). The curriculum of the future: From the 'new sociology of education' to a critical theory of learning. London: Falmer Press.

Zimu-Biyela, N. (2019). Using the School Environmental Education Programme (SEEP) to decolonise the curriculum: Lessons from Ufasimba Primary School in South Africa. International Journal of African Renaissance Studies - Multi-, Inter- and Transdisciplinarity, 14(1), 42-66.

Publisher's Note Springer Nature remains neutral with regard to jurisdictional claims in published maps and institutional affiliations.

Rani Gul is Assistant Professor at the University of Malakand, KPK, Pakistan. Her research spans a wide range of issues covering different domains of educational psychology, linguistics, curriculum, pedagogy, teacher education, and science education. She has been engaged in teaching and supervision activities at undergraduate and postgraduate levels in both private and public sector universities.

Gulab Khilji is currently serving as Deputy Director (Curriculum) at the Bureau of Curriculum Secondary Education Department Balochistan, Quetta. He received his PhD in Curriculum and Instruction, with a concentration in Curriculum Studies, from the University of North Texas, in 2016. He has been working on teacher education, education policy, curriculum, and education assessment in the province of Balochistan. His research interests include curriculum studies, education policy, teacher education, sociocultural theory, and qualitative research. 